\title{
The role of mitochondria in yeast programmed cell death
}

\section{Nicoletta Guaragnella ${ }^{1}$, Maša Ždralević ${ }^{1}$, Lucia Antonacci ${ }^{1}$, Salvatore Passarella ${ }^{2}$, Ersilia Marra ${ }^{1}$ and Sergio Giannattasio ${ }^{1}$ *}

1 Institute of Biomembranes and Bioenergetics, National Research Council of Italy, Bari, Italy

${ }^{2}$ Department of Medicine and Health Sciences, University of Molise, Campobasso, Italy

\section{Edited by:}

Manuela Côrte-Real, Universidade do Minho, Portugal

\section{Reviewed by:}

Gavin McStay, Columbia University, USA

Stephen Tait, University of Glasgow, UK

Maria João Sousa, Universidade do Minho, Portugal

\section{*Correspondence:}

Sergio Giannattasio, Institute of Biomembranes and Bioenergetics, National Research Council of Italy, Via Amendola 165/A, I-70126 Bari, Italy. e-mail:s.giannattasio@ibbe.cnr.it
Mammalian apoptosis and yeast programmed cell death (PCD) share a variety of features including reactive oxygen species production, protease activity and a major role played by mitochondria. In view of this, and of the distinctive characteristics differentiating yeast and multicellular organism PCD, the mitochondrial contribution to cell death in the genetically tractable yeast Saccharomyces cerevisiae has been intensively investigated. In this minireview we report whether and how yeast mitochondrial function and proteins belonging to oxidative phosphorylation, protein trafficking into and out of mitochondria, and mitochondrial dynamics, play a role in PCD. Since in PCD many processes take place over time, emphasis will be placed on an experimental model based on acetic acid-induced PCD (AA-PCD) which has the unique feature of having been investigated as a function of time. As will be described there are at least two AA-PCD pathways each with a multifaceted role played by mitochondrial components, in particular by cytochrome $C$.

Keywords: yeast, programmed cell death, mitochondria, acetic acid, cytochrome $c$, protein trafficking, intracellular signaling
The unicellular yeast Saccharomyces cerevisiae has been established as a good model to elucidate molecular mechanisms underlying programmed cell death (PCD) pathways. S. cerevisiae PCD shares many morphological and biochemical features with apoptosis, the major form of mammalian PCD, although there are some peculiar differences. PCD have been described to occur in yeast in different physiological scenarios (Carmona-Gutierrez et al., 2010). Indeed, chromatin condensation, nuclear DNA fragmentation and phosphatidylserine externalization onto the cell surface are general markers of both mammalian and yeast PCD cells. A characteristic feature of mammalian apoptosis is the activation of caspases, proteases that initiate and execute cell death through degradation of cell components. Yeast contains only one gene homolog of caspases, named YCA1, encoding for yeast metacaspase (Madeo et al., 2002) which has substrate specificity different from caspases (Wilkinson and Ramsdale, 2011). Glyceraldehyde-3-phosphate dehydrogenase has been identified as the first YCA1-specific substrate degraded en route to $\mathrm{H}_{2} \mathrm{O}_{2}$-induced PCD (Silva et al., 2011), but yeast PCD mechanisms occurring both in YCA1-dependent and -independent manner as well as the role of other proteases in yeast PCD remain to be established (Madeo et al., 2009; Wilkinson and Ramsdale, 2011).

Both in yeast and in mammalian PCD mitochondria play a major role in final pro-survival or pro-death decision. Accordingly, the mitochondria-mediated PCD pathway in yeast resembles the mammalian intrinsic pathway, and shows remarkable complexity with respect to different proteins and pathways involved (Eisenberg et al., 2007; Pereira et al., 2008). Alterations in mitochondrial structure and function during PCD depend on a variety of specific triggers, respiratory or fermentative growth conditions, and on overall cell metabolism. First evidence for a mitochondriadependent yeast PCD pathway was obtained in acetic acid-induced
PCD (AA-PCD), with cells showing cytochrome $c$ (cyt $c$ ) release into the cytosol and production of mitochondrial reactive oxygen species (ROS). Mitochondrial dysfunction occurs as shown by mitochondrial depolarization, and a large decrease in cyt $c$ oxidase (COX) activity together with higher resistance to AAPCD of respiratory-deficient cells, lacking either mtDNA or unable to form active cyt $c$ or ATP synthase (Ludovico et al., 2002). Key regulators of mitochondrial metazoan apoptosis are the Bcl-2 family proteins which include both pro-apoptotic and anti-apoptotic members harboring multiple or single Bcl-2 homology $(\mathrm{BH})$ domains $(\mathrm{BH} 1-4)$. These proteins regulate mitochondrial outer membrane permeabilization (MOMP) followed by the release of pro-apoptotic factors including cyt $c$ (Wang and Youle, 2009; Wasilewski and Scorrano, 2009). Recent discovery of a yeast $\mathrm{BH} 3$-only protein (Ybh3p) mediating both AA- and $\mathrm{H}_{2} \mathrm{O}_{2}$-induced PCD (Büttner et al., 2011) supports the hypothesis of the origin of the eukaryotic PCD systems through acquisition of several PCD effectors as a consequence of mitochondrial endosymbiosis (Koonin and Aravind, 2002). Indeed, yeast Ybh3p translocates to mitochondria inducing PCD and mitochondrial membrane depolarization through interaction with the mitochondrial phosphate carrier (Mirlp) and a core subunit of the respiratory complex III (Cor1p; Büttner et al., 2011). Thus, Ybh3p resembles mammalian Bax that can permeabilize mitochondria, whereas mammalian $\mathrm{BH} 3$-only proteins require $\mathrm{Bax}$ and Bak to release cyt $c$, suggesting that the most ancestral function of the BH3-like proteins may be to trigger changes in the IMM (Oettinghaus et al., 2011).

Whether yeast PCD does resemble and/or predate apoptotic death in multicellular organisms or is a distinct form of PCD in itself is still a matter of investigation. Indeed, it remains controversial as to whether metacaspases are distant relatives of caspases 
or are more closely related to other classes of proteases. Moreover even if yeast encodes a $\mathrm{BH} 3$-only protein as recent studies suggest, yeast homologs of $\mathrm{Bcl}-2$ proteins on which $\mathrm{BH} 3$-only proteins act are still unknown. Notwithstanding this, the central role of mitochondria in yeast PCD underlines the importance of dissecting the PCD process in this unicellular organism.

In this review we consider the mitochondrial proteins involved in yeast PCD execution and regulation (see Table 1). Most of them are involved in either electron transfer along the respiratory chain and oxidative phosphorylation, or mitochondrial dynamics, or mitochondrial permeabilization and protein trafficking from mitochondria to cytosol and vice versa. These points will be dealt with separately.

\section{ELECTRON TRANSFER ALONG THE RESPIRATORY CHAIN AND OXIDATIVE PHOSPHORYLATION}

Yeast internal NADH dehydrogenase (NDI1) is the homolog of metazoan AMID, the apoptosis-inducing factor (AIF)homologous mitochondrion-associated inducer of death. Ndilp overexpression can cause PCD, probably due to ROS production in mitochondria, only when cells are grown in glucose-rich media. However this occurs in yeast cells lacking mitochondrial superoxide dismutase both during fermentative and respiring growth (Li et al., 2006). Ymelp is a mitochondrial AAA-type protease involved in the coordinated assembly of COX. Ymelp activation results in a decrease of COX level en route to Bax-induced cell death; however since under fermentative conditions, when COX activity is strongly repressed, YME1 deletion slightly delays Bax-induced cell death, some other unidentified Ymelp substrate could also play a role in this process (Manon et al., 2001). Analysis of the effect of oxidative phosphorylation inhibitors on yeast PCD has shown conflicting results depending on the PCD trigger. Although AA-PCD is insensitive to antimycin or oligomycin, myxothiazol and cyanide prevented amiodarone $/ \alpha$-factor-induced PCD (Ludovico et al., 2002; Pozniakovsky et al., 2005; Guaragnella et al., 2011b). Yeast cells grown in the presence of both antimycin and oligomycin and subsequently treated with acetic acid in the presence of both these compounds displayed a higher sensitivity to AA-PCD (Pereira et al., 2007). Yet, fully assembled and functional $\mathrm{F}_{0} \mathrm{~F}_{1}$-ATPase and cyt $c$ are required for Bax-induced PCD and AA-PCD to occur (Matsuyama et al., 1998; Ludovico et al., 2002; Guaragnella et al., 2011a).

Thus, complexes participating in oxidative phosphorylation have key roles in yeast PCD different from electron transport and ATP synthesis, likely ROS production. Interestingly, deletion of mitochondrial citrate synthase (CIT1) results in higher sensitivity to oxidative stress and PCD induction, due to impairment of reduced glutathione (GSH) biosynthesis (Lee et al., 2007), suggesting that other metabolic pathways are also involved in oxidative stress.

\section{MITOCHONDRIAL DYNAMICS}

Extensive mitochondrial fragmentation is recognized as a general feature in yeast PCD. Fis1p, Dnm1p, and Mdv1p/Net2p, which constitutes the machinery responsible for mitochondrial fission in healthy cells (Fannjiang et al., 2004), are involved in mitochondrial fragmentation/degradation and cell death induced by different stimuli (Fannjiang et al., 2004; Kitagaki et al., 2007; Bink et al., 2010). Indeed, DNM1 gene deletion extends life span by increasing cellular resistance to PCD induction (Scheckhuber et al., 2007). In distinction from its pro-apoptotic function in mammals, yeast Fis1p is a mitochondrial protein which inhibits DNM1-mediated cell death by inhibiting the fission function of Dnm1p, differently from its role in mitochondrial fission during normal growth (Fannjiang et al., 2004). This inhibitory function of Fis1p can be functionally replaced by human $\mathrm{Bcl}-2$ and $\mathrm{Bcl}-\mathrm{x}_{L}$, supporting the idea that Fis1p is a functional homolog of anti-apoptotic Bcl-2 family proteins (Cheng et al., 2008a) and, together with Ybh3p (Büttner et al., 2011), is a component of an ancestral mitochondrial PCD pathway. The pro-survival role of FIS1 was confirmed in studies using different apoptotic triggers, such as virus-encoded toxin, ethanol, and fungicidal derivative BAR0329 (Ivanovska and Hardwick, 2005; Kitagaki et al., 2007; Bink et al., 2010). However, FIS1 may have an additional long-term survival function which appears to be independent of DNM1 and MDV1. Indeed, FIS1 deletion results in acquisition of a secondary mutation in the stress-response gene WHI2 that confers sensitivity to cell death (Cheng et al., 2008b).

Genetic screens have revealed the existence of two novel genes, named yeast suicide protein 1 (YSP1) and yeast suicide protein 2 (YSP2), required for mitochondrial fragmentation en route to amiodarone-induced PCD (Pozniakovsky et al., 2005; Sokolov et al., 2006). It has been proposed that Ysp2p acts downstream of ROS production due to intracellular acidification, following AAPCD induction (Sokolov et al., 2006). No homologous genes have been found in higher organisms.

\section{MITOCHONDRIAL PERMEABILITY AND PROTEIN TRAFFICKING FROM MITOCHONDRIA TO CYTOSOL AND VICE VERSA}

As in mammals, the release of pro-apoptotic mitochondrial proteins occurs en route to yeast PCD. Cyt $c$ was the first mitochondrial protein shown to have an apoptotic function different from its role as an electron carrier in the respiratory chain. Cyt $c$ release from mitochondria occurs commonly in yeast PCD both in response to a variety of stimuli, including acetic acid (Ludovico et al., 2002; Giannattasio et al., 2008), amiodarone/ $\alpha$-factor (Pozniakovsky et al., 2005), $\mathrm{H}_{2} \mathrm{O}_{2}$ (Pereira et al., 2007), aspirin (Sapienza etal., 2008), salt stress (Gao etal., 2011), and as a result of heterologous expression of the mammalian BAX (Manon et al., 1997). Cyt $c$ release was also observed in yeast strains lacking the histone chaperone ASF1/CIA1 (Yamaki et al., 2001) and with a mutation in CDC48 (cdc48 $5565 G$; Braun et al., 2006). Deletion of cyt $c$ isoforms or heme lyase, necessary for cyt $c$ maturation, inhibits yeast PCD triggered by different stimuli (Ludovico et al., 2002; Severin and Hyman, 2002; Pozniakovsky et al., 2005; Silva etal., 2005; Yang etal., 2008; Gao etal., 2011), except ethanol (Kitagaki et al., 2007).

Mammalian AIF is a FAD-containing oxidoreductase localized in the mitochondrial intermembrane space whose specific enzymatic activity remains unknown (Sevrioukova, 2011). AIF is a caspase-independent death effector and also plays a vital mitochondrial role in healthy cells (Hangen et al., 2010). Similarly to AIF, the yeast homolog Aiflp translocates to the nucleus in 
Table 1 | Yeast mitochondrial proteins involved in PCD regulation.

\begin{tabular}{|c|c|c|c|c|}
\hline Gene (protein) & $\begin{array}{l}\text { Mammalian } \\
\text { homolog }\end{array}$ & PCD trigger & Role in PCD & Reference \\
\hline $\begin{array}{l}\text { AAC1/AAC2/AAC3 (ADP/ATP } \\
\text { carrier isoforms) }\end{array}$ & ANT & Acetic acid, diamide, $\mathrm{H}_{2} \mathrm{O}_{2}$ & MOMP & Pereira et al. (2007) \\
\hline AlF1 (apoptosis-inducing factor) & AlF & Acetic acid, bostrycin, $\mathrm{H}_{2} \mathrm{O}_{2}$ & $\begin{array}{l}\text { Pro-apoptotic released factor } \\
\text { translocating to the nucleus }\end{array}$ & $\begin{array}{l}\text { Wissing et al. (2004), } \\
\text { Xu et al. (2010) }\end{array}$ \\
\hline $\begin{array}{l}\text { ATP10 (ATP synthase assembly } \\
\text { factor) }\end{array}$ & ATP synthase & Acetic acid & Pro-apoptotic factor & Ludovico et al. (2002) \\
\hline CIT1 (citrate synthase) & CS & Aging, heat & $\begin{array}{l}\text { GSH biosynthesis, antioxidant } \\
\text { activity }\end{array}$ & Lee etal. (2007) \\
\hline COR1 (complex III core subunit) & QCR1 & Acetic acid + Ybh3 overexpression & ETC, YBH3 interaction & Büttner et al. (2011) \\
\hline $\begin{array}{l}\text { CYC1/CYC7 (cytochrome } c \\
\text { isoforms 1, 2) }\end{array}$ & Cytochrome c & $\begin{array}{l}\text { Acetic acid, amiodarone/ } \alpha \text {-factor, } \\
\text { ASF1/CIA1 deletion, aspirin, } \\
\text { cdc48 } 565 \mathrm{G}, \mathrm{Bax} \text { heterologous } \\
\text { expression, } \mathrm{H}_{2} \mathrm{O}_{2} \text {, hyperosmotic } \\
\text { stress, salt stress }\end{array}$ & $\begin{array}{l}\text { Pro-apoptotic released factor, } \\
\text { ETC electron donor, ROS } \\
\text { scavenger }\end{array}$ & $\begin{array}{l}\text { Manon etal. (1997), } \\
\text { Yamaki etal. (2001), } \\
\text { Ludovico etal. (2002), } \\
\text { Pozniakovsky et al. (2005), } \\
\text { Silva et al. (2005), } \\
\text { Braun et al. (2006), } \\
\text { Pereira et al. (2007), } \\
\text { Giannattasio et al. (2008), } \\
\text { Sapienza et al. (2008), } \\
\text { Gao et al. (2011) }\end{array}$ \\
\hline CYC3 (cytochrome c heme lyase) & $\mathrm{CCHL}$ & $\begin{array}{l}\text { Acetic acid, amiodarone, } \\
\text { hyperosmotic stress }\end{array}$ & Cyt $c$ holoenzyme formation & $\begin{array}{l}\text { Ludovico et al. (2002), } \\
\text { Pozniakovsky et al. (2005), } \\
\text { Silva etal. (2005) }\end{array}$ \\
\hline $\begin{array}{l}\text { FIS1 (mitochondrial fission } \\
\text { protein) }\end{array}$ & $\mathrm{hFIS}$ & $\begin{array}{l}\text { Acetic acid, BAR0329, ethanol, } \\
\text { heat shock, } \mathrm{H}_{2} \mathrm{O}_{2}\end{array}$ & Mitochondrial dynamics & $\begin{array}{l}\text { Fannjiang etal. (2004), } \\
\text { Kitagaki et al. (2007), } \\
\text { Bink et al. (2010) }\end{array}$ \\
\hline $\begin{array}{l}\text { L14-A (mitochondrial 60S } \\
\text { ribosomal protein) }\end{array}$ & - & Grapefruit seed extract & Unknown & Cao et al. (2012) \\
\hline $\begin{array}{l}\text { MIR1 (mitochondrial phosphate } \\
\text { carrier) }\end{array}$ & $\mathrm{PHC}$ & Acetic acid + Ybh3 overexpression & $\begin{array}{l}\text { Energetic metabolism, YBH3 } \\
\text { interaction }\end{array}$ & Büttner etal. (2011) \\
\hline $\begin{array}{l}\text { ND/1 (internal NADH } \\
\text { dehydrogenase) }\end{array}$ & AMID & NDI1 overexpression & ROS production & Li etal. (2006) \\
\hline NUC1 (mitochondrial nuclease) & Endo G & $\begin{array}{l}\text { Acetic acid, amiodarone, ethanol, } \\
\mathrm{H}_{2} \mathrm{O}_{2}\end{array}$ & $\begin{array}{l}\text { Pro-apoptotic released factor } \\
\text { translocating to the nucleus }\end{array}$ & $\begin{array}{l}\text { Büttner et al. (2007), } \\
\text { Kitagaki etal. (2007) }\end{array}$ \\
\hline POR1 (porin) & VDAC & Acetic acid, $\mathrm{H}_{2} \mathrm{O}_{2}$, diamide & Anti-apoptotic factor & Pereira et al. (2007) \\
\hline $\begin{array}{l}R S M 23 \text { (mitochondrial 40S } \\
\text { ribosomal protein) }\end{array}$ & hDAP-3 & YCA1 overexpression & Pro-apoptotic factor & Madeo etal. (2002) \\
\hline $\begin{array}{l}\text { TIM18 (translocase of the inner } \\
\text { mitochondrial membrane) }\end{array}$ & - & Arsenite & MOMP & Du etal. (2007) \\
\hline $\begin{array}{l}\text { YME1 (catalytic subunit of i-AAA } \\
\text { protease complex) }\end{array}$ & - & Heterologous expression of Bax & Complex IV degradation & Manon et al. (2001) \\
\hline YSP1 (yeast suicide protein 1) & - & $\alpha$-Factor, amiodarone & Mitochondrial dynamics & Pozniakovsky et al. (2005) \\
\hline YSP2 (yeast suicide protein 2) & - & Acetic acid, amiodarone & Mitochondrial dynamics & Sokolov et al. (2006) \\
\hline
\end{tabular}

The S. cerevisiae mitochondrial proteins reported in this table have been implicated in PCD induced by different triggers through biochemical and/or genetic studies.

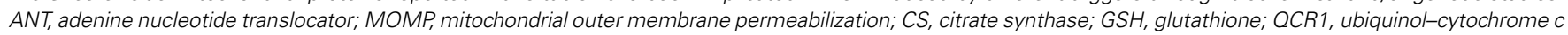

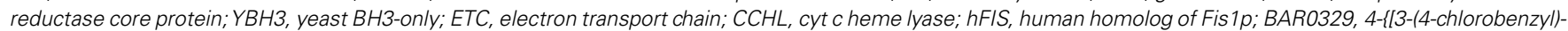

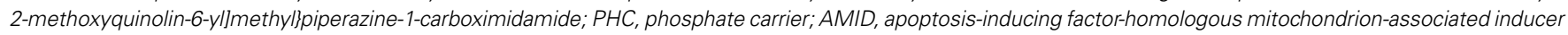
of death; Endo G, endonuclease G; VDAC, voltage-dependent anion channel; hDAP-3, human death associated protein. 
response to apoptotic stimuli (Wissing et al., 2004). AIF1 disruption rescues yeast cells from oxygen stress and delays age-induced PCD. Conversely, overexpression of AIF1 strongly stimulates $\mathrm{H}_{2} \mathrm{O}_{2}$-induced PCD; this effect is attenuated by disruption of YCA1. Contrarily, AIF1-dependent bostrycin-induced cell death was shown to be independent of YCA1 (Xu et al., 2010).

Nuclp is the yeast homolog of metazoan endonuclease G (EndoG), a mitochondrial protein with DNase/RNase activity involved in apoptotic DNA degradation (Li et al., 2001). Overexpression of Nuclp promotes yeast PCD. Nuclp-mediated PCD is shown to be AIF1- and YCA1-independent, which favors the existence of multiple, redundant pathways regulating cell death. Nuclp translocates from mitochondria to the nucleus upon death induction. Nuclp-dependent death depends on its interaction with $A A C 2$, as well as with histone $\mathrm{H} 2 \mathrm{~B}$ and KAP123, coding for karyopherin involved in nuclear import, indicating that the pro-death role of Nuclp requires nuclear import and chromatin association (Büttner et al., 2007). When mitochondrial respiration is increased NUC1 deletion inhibits apoptotic death, whereas under respiration repressing conditions, NUC1 deletion sensitizes yeast cells to non-apoptotic death, this showing a dual, pro-life and pro-death role for NUC1 (Büttner et al., 2007; Kitagaki et al., 2007).

The yeast genome also harbors a gene, called NMA111, homologous to vertebrate HtrA2/Omi mitochondrial serine protease, which mediates apoptosis once released to the cytosol where it can antagonize the inhibitor of apoptosis protein XIAP (Vande Walle et al., 2008). Differently from HtrA2/Omi, yeast Nma111p is a nuclear protein that, under cellular stress conditions such as $\mathrm{H}_{2} \mathrm{O}_{2}$-induced PCD, tends to aggregate inside the nucleus without its expression level being upregulated, suggesting that aggregation of Nma111p is correlated to its death-mediating character (Fahrenkrog et al., 2004).

Mitochondrial protein release and MOMP are crucial events in yeast PCD. Certain mitochondrial proteins possibly involved in MOMP en route to yeast PCD have been identified. Yeast possesses the homologous genes of the putative core components of mammalian permeability transition pore, ADP/ATP carrier proteins $(A A C 1,2,3)$, yeast voltage-dependent anion channel (POR1), and a mitochondrial cyclophilin (CPR3). While Por1p was proposed to have a pro-survival role and Cpr3p had no effect on yeast PCD, only deletion of AAC proteins was shown to protect cells from AA- but not $\mathrm{H}_{2} \mathrm{O}_{2}$-induced PCD, and to inhibit cyt $c$ release (Pereira et al., 2007). In addition, the AAC proteins and the vacuolar protease Pep4p have been shown to have a role in mitochondrial degradation en route to AA-PCD; Pep4p is released from the vacuole upon AA-PCD induction, suggesting a vacuole-mitochondrial cross-talk during yeast PCD (Pereira et al., 2010).

The mitochondrial inner membrane translocase, Tim18, was shown to be involved in arsenic-induced yeast cell death (Du et al., 2007), this raising a question about the possible involvement of this translocase in MOMP. Tim18 is part of the Tim54-Tim22 complex, Tim22 being a mitochondrial receptor for the pro-apoptotic protein Bax (Kovermann et al., 2002).

Two other proteins, Mmilp and Mcd1p, have been shown to translocate to mitochondria en route to yeast PCD. The former functionally links microtubules and mitochondria
(Rinnerthaler etal., 2006). The latter causes the decrease of mitochondrial membrane potential amplifying PCD in a cyt c-dependent manner (Yang et al., 2008).

\section{A CASE STUDY: THE ROLE OF CYTOCHROME $c$ IN YEAST PCD}

Although cyt $c$ release occurs en route to yeast $\mathrm{PCD}$, so far in $S$. cerevisiae there is no evidence of the existence of a functional homolog of the apoptosome (Huttemann et al., 2011). Accordingly, yeast cyt $c$ is unable to activate caspases in cytosolic extracts from metazoan cells (Kluck et al., 2000; Bender et al., 2012). Thus, some questions need to be answered: which event/s triggers cyt $c$ release? Is cyt $c$ released from damaged mitochondria? What is the role of the released cyt $c$ en route to PCD, and is it strictly required for $\mathrm{PCD}$ to occur? In this regard, the definition of the sequence of events leading to the death cascade turns out to be useful.

After the discovery of the occurrence of AA-PCD in yeast (Ludovico et al., 2001, 2002), in a series of papers a detailed time course of certain events was investigated (Giannattasio et al., 2005, 2008; Guaragnella et al., 2006, 2007, 2008, 2010a; Ribeiro et al., 2006; Pereira et al., 2007). These events can be classified as preand post-cyt $c$ release (Figure 1). Loss of cell viability is complete after 200 min of acetic acid treatment with accumulation of cells with fragmented nuclear DNA. The earliest event $(15 \mathrm{~min})$ following acetic acid challenge is ROS production, with a different role for $\mathrm{H}_{2} \mathrm{O}_{2}$ and superoxide anion, whose levels are modulated by catalase and superoxide dismutase. En route to death cyt $c$ starts to be released at $60 \mathrm{~min}$ from coupled and intact mitochondria; maximum release is reached at $150 \mathrm{~min}$. Later on cyt $c$ is degraded, possibly by yet unidentified proteases. The latest event of AA-PCD is caspase-like activation occurring at $200 \mathrm{~min}$ from death induction. Mitochondria are functionally implicated in this death scenario. In fact, up to 150 min released cyt $c$ can act both as an electron donor as well as a ROS scavenger. However, en route to death a progressive impairment of mitochondrial functions, evidenced by a decrease of the respiratory control index, a collapse of the mitochondrial membrane potential, a decrease in COX activity and in cytochromes $a+a_{3}$ levels, have been observed.

The AA-PCD time course clearly shows that ROS accumulation and caspase-like activation occur upstream and downstream of cyt $c$ release, respectively. Functional genomics and biochemical studies on knock-out cells lacking YCA1 and/or the genes encoding the two yeast cyt $c$ isoforms allowed the elucidation of causal relationships among ROS levels, cyt $c$ release and caspase-like activation and two separate pathways activated by acetic acid have been identified. Particularly, it has been found that ROS and YCA1 are required for cyt $c$ release, since both prevention of ROS production by the antioxidant $N$-acetyl cysteine (NAC) and YCA1 disruption result in the inhibition of cyt $c$ release (Guaragnella et al., 2010a,b). How YCA1 is related to cyt $c$ release remains to be elucidated. Nevertheless, a recent report suggests that YCA1 has a role in mitochondrial respiratory functions (Lefevre et al., 2012). Interestingly, AA-PCD still occurs, although with a lower death rate compared to wild type cells, without cyt $c$ release in ADP/ATP carrier as well as YCA1 and/or cyt $c$ knock-out cells (Pereira et al., 2007; Guaragnella et al., 2010b). This confirms on one hand that 


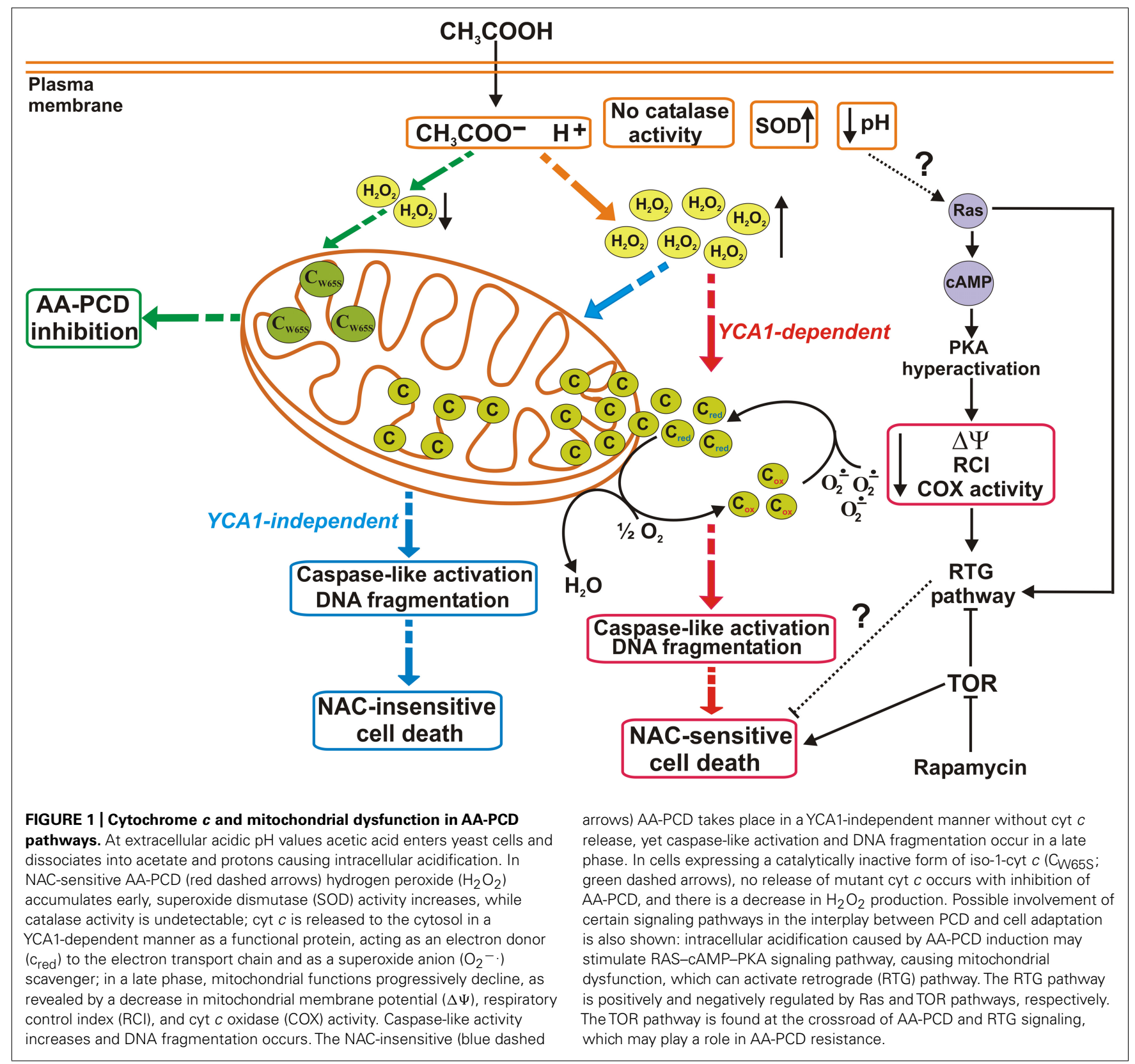

YCA1 and cyt $c$ act as pro-apoptotic proteins in yeast AA-PCD, but on the other hand that they are dispensable for PCD occurrence, showing the existence of YCA1/cyt $c$-independent AA-PCD pathway (Figure 1). In this pathway ROS accumulate early, caspase-like activity increase, and DNA fragmentation occurs. Importantly, $Y C A 1 /$ cyt $c$-independent AA-PCD is insensitive to NAC. This evidence suggests that cyt $c$ still present in mitochondria might play a role in AA-PCD. Recent studies performed on yeast cells expressing a stable but catalytically inactive iso-1-cyt $c$ (W65Scyc1) unable to reduce COX have shown inhibition of $A A-P C D$, with a decrease of ROS production, no cyt $c$ release, this being independent of electron flow impairment, and an increase in caspase-like activation (Figure 1). Thus, cyt $c$ release does not depend on cyt $c$ function as an electron carrier and when still associated to the

mitochondrial membrane, cyt $c$ in its reduced form has a role in AA-PCD by regulating ROS production and caspase-like activity (Guaragnella et al., 2010a,b, 2011b). Regulation of ROS production by mitochondrial cyt $c$ during AA-PCD may be exerted either directly by the cyt $c$ peroxidase system able to scavenge both superoxide anion and $\mathrm{H}_{2} \mathrm{O}_{2}$ (Korshunov et al., 1999) or by a change in cyt $c$-cardiolipin interaction or inefficient cardiolipin peroxidation by ROS (Kagan et al., 2005; Bayir et al., 2006; Sinibaldi et al., 2010; Huttemann et al., 2011). These issues require further investigations.

\section{CONCLUSIONS AND PERSPECTIVES}

In the light of results emerging from research into yeast PCD we feel that there is consensus that the response to any stimulus 
leading to PCD depends on the intrinsic status of the cells, for instance the growth phase or the metabolic and environmental conditions. Paradigmatic of this is that in response to acetic acid in cells with increased mitochondrial respiration yeast activates a Nuclp-dependent PCD pathway (Büttner et al., 2007), whereas in stationary growth phase yeast is less sensitive to acetic acid (Ludovico et al., 2002), and after acid stress adaptation it is highly resistant to AA-PCD induction (Giannattasio et al., 2005; Ždralević et al., 2012).

Although a number of mitochondrial proteins participating in yeast PCD have been identified, how they work en route to PCD remains to be fully established. Further aspects also need to be investigated, including the fact that mitochondria are important organelles in the cross-talk between death- and life-promoting signaling pathways. Indeed, RAS-cAMP-PKA (Longo, 2003; Roosen et al., 2005; Gourlay et al., 2006; Leadsham and Gourlay, 2010), target of rapamycin (TOR) kinase (Almeida et al., 2009) and retrograde (Jazwinsky, 2003; Liu and Butow, 2006) signaling pathways have been shown to control yeast cell PCD and aging through mitochondrial function regulation (Figure 1).

\section{REFERENCES}

Almeida, B., Ohlmeier, S., Almeida, A. J., Madeo, F., Leao, C., Rodrigues, F., and Ludovico, P. (2009). Yeast protein expression profile during acetic acidinduced apoptosis indicates causal involvement of the TOR pathway. Proteomics 9, 720-732.

Bayir, H., Fadeel, B., Palladino, M. J., Witasp, E., Kurnikov, I. V., Tyurina, Y. Y., Tyurin, V. A., Amoscato, A. A., Jiang, J., Kochanek, P. M., Dekosky, S. T., Greenberger, J. S., Shvedova, A. A., and Kagan, V. E. (2006). Apoptotic interactions of cytochrome $c$ : redox flirting with anionic phospholipids within and outside of mitochondria. Biochim. Biophys. Acta 1757, 648-659.

Bender, C. E., Fitzgerald, P., Tait, S. W., Llambi, F., Mcstay, G. P., Tupper, D. O., Pellettieri, J., Sanchez Alvarado, A., Salvesen, G. S., and Green, D. R. (2012). Mitochondrial pathway of apoptosis is ancestral in metazoans. Proc. Natl. Acad. Sci. U.S.A. 109, 4904-4909.

Bink, A., Govaert, G., Francois, I. E., Pellens, K., Meerpoel, L., Borgers, M., Van Minnebruggen, G., Vroome, V., Cammue, B. P., and Thevissen, K. (2010). A fungicidal piperazine1-carboxamidine induces mitochondrial fission-dependent apoptosis in yeast. FEMS Yeast Res. 10, 812-818.

Braun, R. J., Zischka, H., Madeo, F., Eisenberg, T., Wissing, S., Büttner, S., Engelhardt, S. M., Buringer, D., and Ueffing, M. (2006). Crucial mitochondrial impairment upon CDC48 mutation in apoptotic yeast. J. Biol. Chem. 281, 25757-25767.
Büttner, S., Eisenberg, T., CarmonaGutierrez, D., Ruli, D., Knauer, H. Ruckenstuhl, C., Sigrist, C., Wissing, S., Kollroser, M., Frohlich, K. U., Sigrist, S., and Madeo, F. (2007). Endonuclease $\mathrm{G}$ regulates budding yeast life and death. Mol. Cell 25, 233-246.

Büttner, S., Ruli, D., Vogtle, F. N., Galluzzi, L., Moitzi, B., Eisenberg, T. Kepp, O., Habernig, L., CarmonaGutierrez, D., Rockenfeller, P., Laun, P., Breitenbach, M., Khoury, C., Frohlich, K. U., Rechberger, G., Meisinger, C., Kroemer, G., and Madeo, F. (2011). A yeast BH3-only protein mediates the mitochondrial pathway of apoptosis. EMBO J. 30 2779-2792.

Cao, S., Xu, W., Zhang, N., Wang, Y., Luo, Y., He, X., and Huang, K. (2012). A mitochondria-dependent pathway mediates the apoptosis of GSEinduced yeast. PLOS ONE 7, e32943. doi: 10.1371/journal.pone.0032943

Carmona-Gutierrez, D., Eisenberg, T. Büttner, S., Meisinger, C., Kroemer, G., and Madeo, F. (2010). Apoptosis in yeast: triggers, pathways, subroutines. Cell Death Differ. 17, 763-773.

Cheng, W. C., Leach, K. M., and Hardwick, J. M. (2008a). Mitochondrial death pathways in yeast and mammalian cells. Biochim. Biophys. Acta 1783, 1272-1279.

Cheng, W. C., Teng, X., Park, H. K., Tucker, C. M., Dunham, M. J., and Hardwick, J. M. (2008b). Fis1 deficiency selects for compensatory mutations responsible for cell death and growth control defects. Cell Death Differ. 15, 1838-1846.

Mitochondrial dysfunction and the mode of cell response to it underlie different pathological conditions such as neurodegeneration. Alterations in mitochondrial functions have long been observed also in cancer cells and targeting mitochondria as an anti-cancer therapeutic strategy has gained momentum recently (Gogvadze et al., 2009). Since yeast shares with cancer cells the metabolic features identified as the underlying causes of the Warburg effect (Ruckenstuhl et al., 2009; Diaz-Ruiz et al., 2010), it is a suitable model organism to identify cell compounds responsible for tumorigenesis for development of targeted cancer drugs.

\section{ACKNOWLEDGMENTS}

This work was financed by Fondazione Cassa di Risparmio di Puglia to Nicoletta Guaragnella, CNR project MERIT to Ersilia Marra, and a grant from the Italian Ministry of Economy and Finance to the CNR for the Project FaReBio di Qualità to Sergio Giannattasio. Maša Ždralević is a recipient of a CNR PhD fellowship in "Biology and Biotechnologies," Università del Salento, Italy. Lucia Antonacci is a recipient of a CNR contract granted by Fondazione Cassa di Risparmio di Puglia. We thank Professor Shawn Doonan for critically reading of the manuscript.

Diaz-Ruiz, R., Rigoulet, M., and Devin, A. (2010). The Warburg and Crabtree effects: on the origin of cancer cell energy metabolism and of yeast glucose repression. Biochim. Biophys. Acta 1807, 568-576.

Du, L., Yu, Y., Li, Z., Chen, J., Liu, Y., Xia, Y., and Liu, X. (2007). Tim18, a component of the mitochondrial translocator, mediates yeast cell death induced by arsenic. Biochemistry (Mosc) 72, 843-847.

Eisenberg, T., Büttner, S., Kroemer, G., and Madeo, F. (2007). The mitochondrial pathway in yeast apoptosis. Apoptosis 12, 1011-1023.

Fahrenkrog, B., Sauder, U., and Aebi, U. (2004). The S. cerevisiae HtrA-like protein Nmalllp is a nuclear serine protease that mediates yeast apoptosis. J. Cell Sci. 117, 115-126.

Fannjiang, Y., Cheng, W. C., Lee, S. J. Qi, B., Pevsner, J., Mccaffery, J. M., Hill, R. B., Basanez, G., and Hardwick, J. M. (2004). Mitochondrial fission proteins regulate programmed cell death in yeast. Genes Dev. 18 , 2785-2797.

Gao, Q., Ren, Q., Liou, L. C. Bao, X., and Zhang, Z. (2011) Mitochondrial DNA protects against salt stress-induced cytochrome $c$ mediated apoptosis in yeast. FEBS Lett. 585, 2507-2512.

Giannattasio, S., Atlante, A., Antonacci, L., Guaragnella, N., Lattanzio, P. Passarella, S., and Marra, E. (2008). Cytochrome $c$ is released from coupled mitochondria of yeast en route to acetic acid-induced programmed cell death and can work as an electron donor and a ROS scavenger. FEBS Lett. 582, 1519-1525.

Giannattasio, S., Guaragnella, N., Corte-Real, M., Passarella, S., and Marra, E. (2005). Acid stress adaptation protects Saccharomyces cerevisiae from acetic acid-induced programmed cell death. Gene 354, 93-98.

Gogvadze, V., Orrenius, S., and Zhivotovsky, B. (2009). Mitochondria as targets for cancer chemotherapy. Semin. Cancer Biol. 19, 57-66.

Gourlay, C. W., Du, W., and Ayscough, K. R. (2006). Apoptosis in yeast mechanisms and benefits to a unicellular organism. Mol. Microbiol. 62, 1515-1521.

Guaragnella, N., Antonacci, L., Giannattasio, S., Marra, E., and Passarella, S. (2008). Catalase T and Cu,Znsuperoxide dismutase in the acetic acid-induced programmed cell death in Saccharomyces cerevisiae. FEBS Lett. 582, 210-214.

Guaragnella, N., Antonacci, L., Passarella, S., Marra, E., and Giannattasio, S. (2007). Hydrogen peroxide and superoxide anion production during acetic acid-induced yeast programmed cell death. Folia Microbiol. 7, 237-240.

Guaragnella, N., Antonacci, L., Passarella, S., Marra, E., and Giannattasio, S. (2011a). Achievements and perspectives in yeast acetic acid-induced programmed cell death pathways. Biochem. Soc. Trans. 39, 1538-1543.

Guaragnella, N., Passarella, S., Marra, E., and Giannattasio, S. (2011b). Cytochrome $c$ Trp65Ser substitution 
results in inhibition of acetic acidinduced programmed cell death in Saccharomyces cerevisiae. Mitochondrion 11, 987-991.

Guaragnella, N., Bobba, A., Passarella, S., Marra, E., and Giannattasio, S. (2010a). Yeast acetic acid-induced programmed cell death can occur without cytochrome $c$ release which requires metacaspase YCA1. FEBS Lett. 584, 224-228.

Guaragnella, N., Passarella, S., Marra, E., and Giannattasio, S. (2010b). Knock-out of metacaspase and/or cytochrome $c$ results in the activation of a ROS-independent acetic acid-induced programmed cell death pathway in yeast. FEBS Lett. 584, 3655-3660.

Guaragnella, N., Pereira, C., Sousa, M. J., Antonacci, L., Passarella, S., Corte-Real, M., Marra, E., and Giannattasio, S. (2006). YCA1 participates in the acetic acid induced yeast programmed cell death also in a manner unrelated to its caspase-like activity. FEBS Lett. 580, 6880-6884.

Hangen, E., Blomgren, K., Benit, P., Kroemer, G., and Modjtahedi, N. (2010). Life with or without AIF. Trends Biochem. Sci. 35, 278-287.

Huttemann, M., Pecina, P., Rainbolt, M., Sanderson, T. H., Kagan, V. E., Samavati, L., Doan, J. W., and Lee, I. (2011). The multiple functions of cytochrome $c$ and their regulation in life and death decisions of the mammalian cell: from respiration to apoptosis. Mitochondrion 11, 369-381.

Ivanovska, I., and Hardwick, J. M. (2005). Viruses activate a genetically conserved cell death pathway in a unicellular organism. J. Cell Biol. 170, 391-399.

Jazwinsky, M. S. (2003). "Mitochondria, metabolism and aging in yeast," in Model Systems in Aging, eds T. Nystrom and H. D. Osiewacz (Heidelberg: Springer), 39-59.

Kagan, V. E., Tyurin, V. A., Jiang, J., Tyurina, Y. Y., Ritov, V. B., Amoscato, A. A., Osipov, A. N., Belikova, N. A., Kapralov, A. A., Kini, V., Vlasova, Ii, Zhao, Q., Zou, M., Di, P., Svistunenko, D. A., Kurnikov, I. V., and Borisenko, G. G. (2005). Cytochrome $c$ acts as a cardiolipin oxygenase required for release of proapoptotic factors. Nat. Chem. Biol. 1, 223-232.

Kitagaki, H., Araki, Y., Funato, K., and Shimoi, H. (2007). Ethanol-induced death in yeast exhibits features of apoptosis mediated by mitochondrial fission pathway. FEBS Lett. 581, 2935-2942.
Kluck, R. M., Ellerby, L. M., Ellerby, H. M., Naiem, S., Yaffe, M. P., Margoliash, E., Bredesen, D., Mauk, A. G. Sherman, F., and Newmeyer, D. D. (2000). Determinants of cytochrome $c$ pro-apoptotic activity. The role of lysine 72 trimethylation. J. Biol. Chem. 275, 16127-16133.

Koonin, E. V., and Aravind, L. (2002). Origin and evolution of eukaryotic apoptosis: the bacterial connection. Cell Death Differ. 9, 394-404.

Korshunov, S. S., Krasnikov, B. F., Pereverzev, M. O., and Skulachev, V. P. (1999). The antioxidant functions of cytochrome $c$. FEBS Lett. 462, 192-198.

Kovermann, P., Truscott, K. N., Guiard, B., Rehling, P., Sepuri, N. B., Muller, H., Jensen, R. E., Wagner, R., and Pfanner, N. (2002). Tim22, the essential core of the mitochondrial protein insertion complex, forms a voltageactivated and signal-gated channel. Mol. Cell 9, 363-373.

Leadsham, J. E., and Gourlay, C. W. (2010). cAMP/PKA signaling balances respiratory activity with mitochondria dependent apoptosis via transcriptional regulation. BMC Cell Biol. 11, 92. doi: 10.1186/1471-212111-92

Lee, Y. J., Hoe, K. L., and Maeng, P. J. (2007). Yeast cells lacking the CIT1encoded mitochondrial citrate synthase are hypersusceptible to heat- or aging-induced apoptosis. Mol. Biol. Cell 18, 3556-3567.

Lefevre, S., Sliwa, D., Auchere, F., Brossas, C., Ruckenstuhl, C., Boggetto, N., Lesuisse, E., Madeo F., Camadro, J. M., and Santos, R. (2012). The yeast metacaspase is implicated in oxidative stress response in frataxin-deficient cells. FEBS Lett. 586, 143-148.

Li, L. Y., Luo, X., and Wang, X. (2001). Endonuclease G is an apoptotic DNase when released from mitochondria. Nature 412 , 95-99.

Li, W., Sun, L., Liang, Q., Wang, J., Mo, W., and Zhou, B. (2006). Yeast AMID homologue Ndilp displays respiration-restricted apoptotic activity and is involved in chronological aging. Mol. Biol. Cell 17, 1802-1811.

Liu, Z., and Butow, R. A. (2006). Mitochondrial retrograde signaling. Annu. Rev. Genet. 40, 159-185.

Longo, V. D. (2003). The Ras and Sch9 pathways regulate stress resistance and longevity. Exp. Gerontol. 38, 807-811.

Ludovico, P., Rodrigues, F., Almeida, A., Silva, M. T., Barrientos, A., and Corte-Real, M. (2002). Cytochrome $c$ release and mitochondria involvement in programmed cell death induced by acetic acid in Saccha romyces cerevisiae. Mol. Biol. Cell 13 2598-2606.

Ludovico, P., Sousa, M. J., Silva, M. T. Leao, C., and Corte-Real, M. (2001). Saccharomyces cerevisiae commits to a programmed cell death process in response to acetic acid. Microbiology 147, 2409-2415.

Madeo, F., Carmona-Gutierrez, D., Ring, J., Büttner, S., Eisenberg, T., and Kroemer, G. (2009). Caspasedependent and caspase-independent cell death pathways in yeast. Biochem. Biophys. Res. Commun. 382, 227-231.

Madeo, F., Herker, E., Maldener, C., Wissing, S., Lachelt, S., Herlan, M., Fehr, M., Lauber, K., Sigrist, S. J., Wesselborg, S., and Frohlich, K. U. (2002). A caspase-related protease regulates apoptosis in yeast. Mol. Cell 9, 911-917.

Manon, S., Chaudhuri, B., and Guerin, M. (1997). Release of cytochrome $c$ and decrease of cytochrome $c$ oxidase in Bax-expressing yeast cells, and prevention of these effects by coexpression of Bcl-xL. FEBS Lett. 415, 29-32.

Manon, S., Priault, M., and Camougrand, N. (2001). Mitochondrial AAA-type protease Ymelp is involved in Bax effects on cytochrome c oxidase. Biochem. Biophys. Res. Commun. 289, 1314-1319.

Matsuyama, S., Xu, Q., Velours, J., and Reed, J. C. (1998). The mitochondrial F0F1-ATPase proton pump is required for function of the proapoptotic protein Bax in yeast and mammalian cells. Mol. Cell 1, 327-336.

Oettinghaus, B., Frank, S., and Scorrano, L. (2011). Tonight, the same old, deadly programme: BH3-only proteins, mitochondria and yeast. EMBO J. 30, 2754-2756.

Pereira, C., Camougrand, N., Manon, S., Sousa, M. J., and CorteReal, M. (2007). ADP/ATP carrier is required for mitochondrial outer membrane permeabilization and cytochrome $c$ release in yeast apoptosis. Mol. Microbiol. 66 571-582.

Pereira, C., Chaves, S., Alves, S., Salin, B., Camougrand, N., Manon, S. Sousa, M. J., and Corte-Real, M. (2010). Mitochondrial degradation in acetic acid-induced yeast apoptosis: the role of Pep4 and the ADP/ATP carrier. Mol. Microbiol. 76, 1398-1410.

Pereira, C., Silva, R. D., Saraiva, L., Johansson, B., Sousa, M.
J., and Corte-Real, M. (2008). Mitochondria-dependent apoptosis in yeast. Biochim. Biophys. Acta 1783 , 1286-1302.

Pozniakovsky, A. I., Knorre, D. A., Markova, O. V., Hyman, A. A., Skulachev, V. P., and Severin, F. F. (2005). Role of mitochondria in the pheromone- and amiodaroneinduced programmed death of yeast. J. Cell Biol. 168, 257-269.

Ribeiro, G. F., Corte-Real, M., and Johansson, B. (2006). Characterization of DNA damage in yeast apoptosis induced by hydrogen peroxide, acetic acid, and hyperosmotic shock. Mol. Biol. Cell 17, 4584-4591.

Rinnerthaler, M., Jarolim, S., Heeren, G., Palle, E., Perju, S., Klinger, H., Bogengruber, E., Madeo, F., Braun, R. J., Breitenbach-Koller, L., Breitenbach, M., and Laun, P. (2006). MMI1 (YKL056c, TMA19), the yeast orthologue of the translationally controlled tumor protein (TCTP) has apoptotic functions and interacts with both microtubules and mitochondria. Biochim. Biophys. Acta 1757, 631-638.

Roosen, J., Engelen, K., Marchal, K., Mathys, J., Griffioen, G., Cameroni, E., Thevelein, J. M., De Virgilio, C., De Moor, B., and Winderickx, J. (2005). PKA and Sch9 control a molecular switch important for the proper adaptation to nutrient availability. Mol. Microbiol. 55, 862-880.

Ruckenstuhl, C., Büttner, S., CarmonaGutierrez, D., Eisenberg, T., Kroemer, G., Sigrist, S. J., Frohlich, K. U., and Madeo, F. (2009). The Warburg effect suppresses oxidative stress induced apoptosis in a yeast model for cancer. PLoS ONE 4, e4592. doi: 10.1371/journal.pone. 0004592

Sapienza, K., Bannister, W., and Balzan, R. (2008). Mitochondrial involvement in aspirin-induced apoptosis in yeast. Microbiology 154, 2740-2747.

Scheckhuber, C. Q., Erjavec, N., Tinazli, A., Hamann, A., Nystrom, T., and Osiewacz, H. D. (2007). Reducing mitochondrial fission results in increased life span and fitness of two fungal ageing models. Nat. Cell Biol. 9, 99-105.

Severin, F. F., and Hyman, A. A. (2002). Pheromone induces programmed cell death in $S$. cerevisiae. Curr. Biol. 12, R233-R235.

Sevrioukova, I. F. (2011). Apoptosisinducing factor: structure, function, and redox regulation. Antioxid. Redox Signal. 14, 2545-2579. 
Silva, A., Almeida, B., SampaioMarques, B., Reis, M. I., Ohlmeier, S., Rodrigues, F., Vale, A., and Ludovico, P. (2011). Glyceraldehyde-3-phosphate dehydrogenase (GAPDH) is a specific substrate of yeast metacaspase. Biochim. Biophys. Acta 1813, 2044-2049.

Silva, R. D., Sotoca, R., Johansson, B., Ludovico, P., Sansonetty, F., Silva, M. T., Peinado, J. M., and CorteReal, M. (2005). Hyperosmotic stress induces metacaspase- and mitochondria-dependent apoptosis in Saccharomyces cerevisiae. Mol. Microbiol. 58, 824-834.

Sinibaldi, F., Howes, B. D., Piro, M. C., Polticelli, F., Bombelli, C., Ferri, T., Coletta, M., Smulevich, G., and Santucci, R. (2010). Extended cardiolipin anchorage to cytochrome $c$ : a model for protein-mitochondrial membrane binding. J. Biol. Inorg. Chem. 15, 689-700.

Sokolov, S., Knorre, D., Smirnova, E. Markova, O., Pozniakovsky, A., Skulachev, V., and Severin, F. (2006). Ysp2 mediates death of yeast induced by amiodarone or intracellular acidification. Biochim. Biophys. Acta 1757, 1366-1370.

Vande Walle, L., Lamkanfi, M., and Vandenabeele, P. (2008). The mitochondrial serine protease HtrA2/Omi: an overview. Cell Death Differ. 15, 453-460.

Wang, C., and Youle, R. J. (2009). The role of mitochondria in apoptosis*. Annu. Rev. Genet. 43, 95-118.

Wasilewski, M., and Scorrano, L. (2009). The changing shape of mitochondrial apoptosis. Trends Endocrinol. Metab. 20, 287-294.

Wilkinson, D., and Ramsdale, M. (2011). Proteases and caspase-like activity in the yeast Saccharomyces cerevisiae. Biochem. Soc. Trans. 39, 1502-1508.

Wissing, S., Ludovico, P., Herker, E., Büttner, S., Engelhardt, S. M., Decker, T., Link, A., Proksch, A., Rodrigues, F., Corte-Real, M., Frohlich, K. U., Manns, J., Cande, C., Sigrist, S. J., Kroemer, G., and Madeo, F. (2004). An AIF orthologue regulates apoptosis in yeast. J. Cell Biol. 166, 969-974.

$\mathrm{Xu}$, C., Wang, J., Gao, Y., Lin, H., Du, L., Yang, S., Long, S., She, Z., Cai, X., Zhou, S., and Lu, Y. (2010). The anthracenedione compound bostrycin induces mitochondria-mediated apoptosis in the yeast Saccharomyces cerevisiae. FEMS Yeast Res. 10, 297-308.

Yamaki, M., Umehara, T., Chimura, T., and Horikoshi, M. (2001). Cell death with predominant apoptotic features in Saccharomyces cerevisiae mediated by deletion of the histone chaperone ASF1/CIA1. Genes Cells 6, 1043-1054.

Yang, H., Ren, Q., and Zhang, Z. (2008). Cleavage of Mcdl by caspase-like protease Esp1 promotes apoptosis in budding yeast. Mol. Biol. Cell 19, 2127-2134.

Ždralević, M., Guaragnella, N. Antonacci, L., Marra, E., and Giannattasio, S. (2012). Yeast as a too to study signaling pathways in mitochondrial stress response and cytoprotection. Sci. World J. 2012, 912147.
Conflict of Interest Statement: The authors declare that the research was conducted in the absence of any commercial or financial relationships that could be construed as a potential conflict of interest.

Received: 05 April 2012; accepted: 14 June 2012; published online: 03 July 2012.

Citation: Guaragnella N, Ždralević M, Antonacci L, Passarella S, Marra E and Giannattasio S (2012) The role of mitochondria in yeast programmed cell death. Front. Oncol. 2:70. doi: 10.3389/ fonc.2012.00070

This article was submitted to Frontiers in Molecular and Cellular Oncology, a specialty of Frontiers in Oncology.

Copyright () 2012 Guaragnella Ždralević, Antonacci, Passarella, Marra and Giannattasio. This is an open-access article distributed under the terms of the Creative Commons Attribution License, which permits use, distribution and reproduction in other forums, provided the original authors and source are credited and subject to any copyright notices concerning any third-party graphics etc. 